\title{
An Interfacial Study of Borosilicate Glass and Fe-Ni-Co Alloy Joint
}

\author{
C. Chanmuang* and T. Chairuangsri** \\ * Department of Physics, Chiang Mai University, Chiang Mai, 50200, Thailand \\ ** Department of Industrial Chemistry, Chiang Mai University, Chiang Mai, 50200, Thailand
}

\section{Introduction}

Borosilicate glass to Fe-Ni-Co alloy joint has been used for many years as hermetic and electrically insulating seals. It is not only excellent in thermal expansion matching but also in good wettability and bond strength [1]. By using electron probe microanalysis and scanning electron microscopy (SEM), it was reported that the oxide scale preformed on the alloy surface was dissolved during joining into the glass, forming a zone enriched in Fe resulting in chemical bonding and good matching of thermal expansion coefficient [1-3]. Mechanical bonding by penetration of the FeOriched glass into the open porosity at the alloy surface was also observed [3]. However, interfacial study by transmission electron microscopy (TEM) has not been attempted, which is the aim of this work, to gain more direct evidence on the mechanism of adhesion between both materials.

\section{Materials and Methods}

The joints of a borosilicate glass to an Fe-Ni-Co alloy in a commercial, medical x-ray tube were studied. The cross-sectional TEM specimens were prepared to electron transparency by dimpling together with electrochemical polishing and ion milling. The interfacial microstructure was studied by using JEOL JSM-6335F SEM and JEOL JEM-2010 TEM-STEM operated at $200 \mathrm{kV}$.

\section{Results and Discussion}

The microstructure at the glass-alloy interface can be divided into four regions (Fig 1a). Region I is an alloy with no change in chemical composition. Region II is the porous Fe-depleted area underneath the alloy surface. The thickness of porous layers on the left- and the right-hand side interface (Fig. 1b and 1c) is approximately $5 \mu \mathrm{m}$ and $25 \mu \mathrm{m}$. The glass penetrating into these open pores should create a strong mechanical bonding. These porous layers are enriched in $\mathrm{Ni}$ and also in Co. Region III is the Fe-riched zone in the glass, while Region IV is the bulk of the glass. X-ray line scans in TEM investigation (Fig. 2) revealed that not only Fe but also Ni and Co were dissolved into the glass. $\mathrm{Ni}$ and Co must therefore be involved in chemical bonding between the glass and the alloy. Moreover, particles of iron silicate $\left(\mathrm{Fe}_{2} \mathrm{SiO}_{4}\right)$ and iron silicon carbonyl $\left(\mathrm{SiFe}_{4}(\mathrm{CO})_{16}\right)$ with the size of about 10-100 nm were found within the glass in this area (Fig. 3).

\section{Conclusion}

SEM and TEM investigations confirmed chemical bonding by dissolvation of $\mathrm{Fe}$ into the glass and mechanical bonding by penetration of the FeO-riched glass into the porous layer on the alloy surface. However, TEM observation revealed also dissolvation of $\mathrm{Ni}$ and $\mathrm{Co}$ into the glass suggesting that these elements must be involved in chemical bonding. Devitrification of $\mathrm{Fe}_{2} \mathrm{SiO}_{4}$ and $\mathrm{SiFe}_{4}(\mathrm{CO})_{16}$ was found as fine particles within the glass at the vicinity close to the interface.

\section{References}

[1] C.J. Macey et al., Appl. Surf. Sci. 21 (1985) 139.

[2] Y. Ikeda and Y.Sameshima, The Seventh Japan Congress on Testing Materials-Non-Metallic Materials, (1964) 127.

[3] A. Zanchetta, et al., J. Eur. Ceram. Soc. 15 (1995) 233.

[4] The Royal Thai Government Scholarship and Graduate School of Chiang Mai University are gratefully thanked for funding support of this research. 

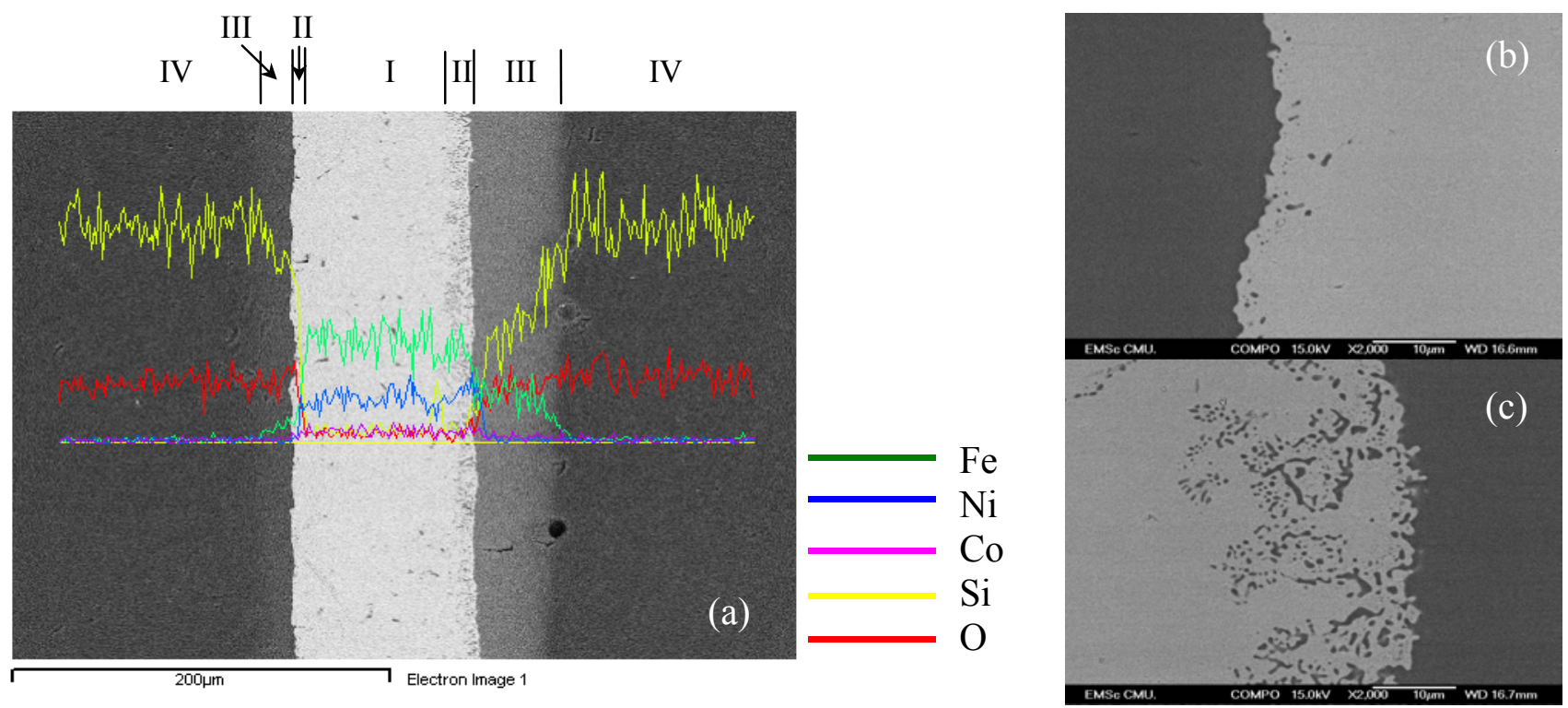

Fig. 1 (a) A SEM micrograph and x-ray line scans showing a cross section and distribution of elements at the borosilicate glass and Fe-Ni-Co alloy joint, (b) the left-hand side interface in (a), and (c) the right-hand side interface in (a).
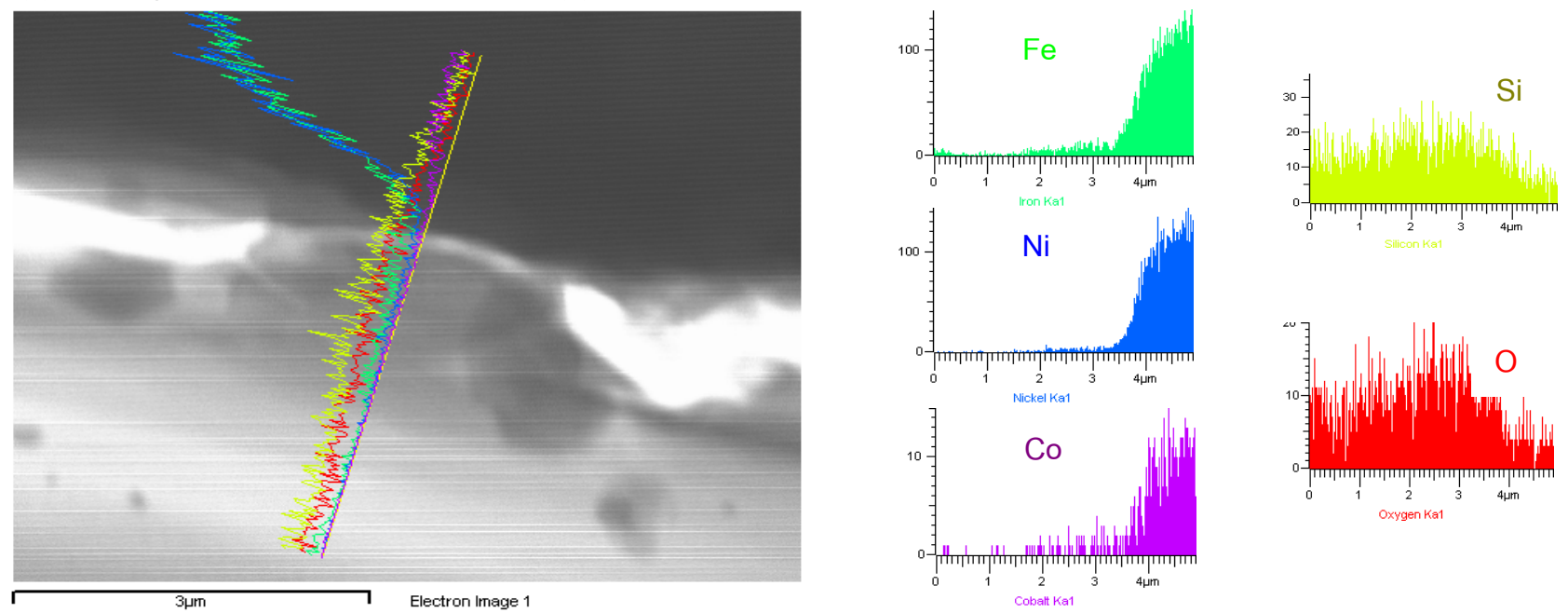

Fig. 2 A bright field TEM micrograph and STEM x-ray line scans at the borosilicate glass and Fe-Ni-Co alloy interface in Fig. 1(b).

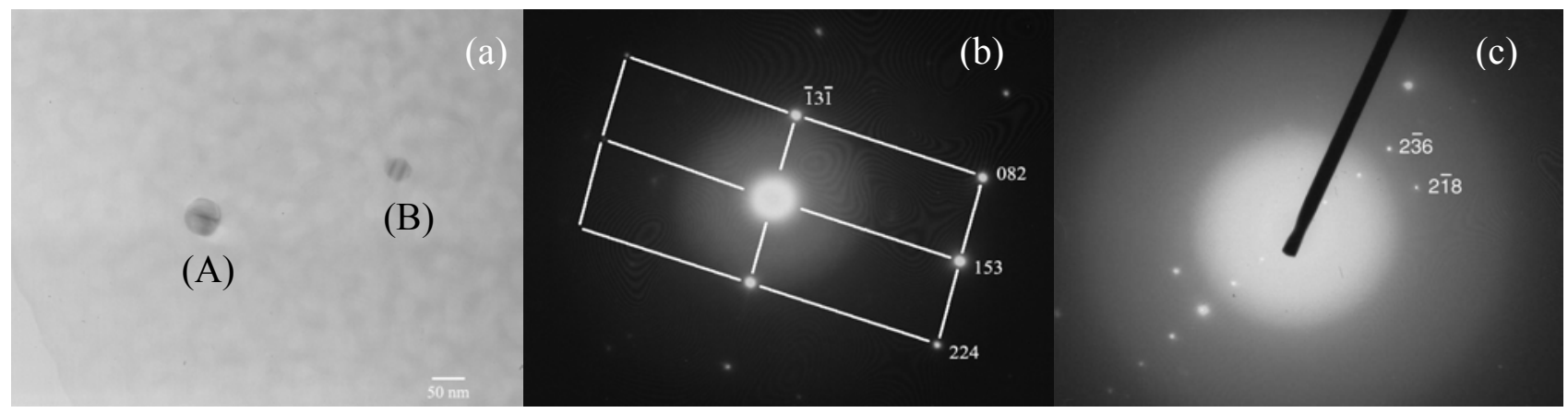

Fig. 3 (a) A bright field TEM micrograph showing precipitated particles within the glass at the area closed to the glass-alloy interface in Fig. 2, (b) and (c) are selected area diffraction patterns from particle $\mathrm{A}\left(\mathrm{Fe}_{2} \mathrm{SiO}_{4}\right)$ and $\mathrm{B}\left(\mathrm{SiFe}_{4}(\mathrm{CO})_{16}\right)$, respectively. 